\title{
Short left coronary artery trunk as a risk factor in the development of coronary atherosclerosis Pathological study
}

\author{
N. Gazetopoulos, P. J. Ioannidis, C. Karydis, C. Lolas, K. Kiriakou, and C. Tountas \\ From the Cardiology Division, 2nd Department of Surgery, Aretaeion Hospital, Athens University, Athens, \\ Greece
}

The relation between the length of the main left coronary artery and the degree of atherosclerosis in its branches was studied by postmortem examination in 204 subjects aged 20 to 90 years.

The findings suggest that in cases with a short main left coronary artery the atherosclerotic lesions in the anterior descending and circumflex branches appear earlier, progress faster at higher levels of severity, and lead more frequently to myocardial infarction, than in cases with a long left coronary artery trunk. In cases over the age of 50 years, where disease is expected to have developed, it was shown that the degree of atherosclerosis in the left anterior descending and circumflex branches was inversely related to the length of the main left coronary artery. The correlation coefficients were -0.527 and -0.428 , respectively, and in either case a test for zero correlation was significant $(P<0 \cdot 001)$.

The possible changes in the haemodynamic and mechanical conditions associated with the variations of the anatomical pattern of the coronary arteries and their influence in the development of atherosclerosis are discussed. It is suggested that the length of the main left coronary artery is a congenital anatomical and possibly hereditary factor influencing the rate of development of atherosclerosis in the branches of the main left coronary artery.

The involvement of local mechanical and haemodynamic factors in the development of atherosclerosis of the coronary arteries is a generally accepted fact and the significance of such factors has been emphasized in recent publications (Glagov, 1972; Fry, 1972; Texon, 1974; Stehbens, 1975).

In a coronary arteriographic study from our department, we found that patients with a short main left coronary artery showed a high degree of atherosclerosis in its branches (Gazetopoulos et al., 1976). This finding was attributed to the haemodynamic conditions associated with this anatomical pattern. However, the study was based on limited material derived mainly from patients suffering either from advanced coronary artery disease or valvular heart disease, who were candidates for heart surgery. Furthermore, these observations were indirect being based on coronary arteriographic appearance. For this reason a further study

Received 9 February 1976. based on direct observation of a larger, randomly selected series of cases, was undertaken.

This paper deals with pathological observations on the presence of atherosclerosis in relation to the length of the main left coronary artery.

\section{Subjects and methods}

The coronary arteries were examined in 204 subjects (120 men and 84 women) aged 20 to 90 years who died suddenly or violently and were transferred to the Athens morgue for determination of the cause of death. Age and sex distribution are shown in Table 1. The cause of death was accident (76 cases), acute myocardial infarction (50 cases), cerebrovascular or vascular accident (42 cases), and miscellaneous diseases other than cardiovascular (36 cases).

The coronary arteries were dissected along the vessel's lumen and under direct observation the atheromatous lesions of the left anterior descending, 
TABLE 1 Age and sex distribution

\begin{tabular}{lcccccc}
\hline Age $(y)$ & $\begin{array}{l}\text { Men } \\
\text { Short }\end{array}$ & Long $\dagger$ & Total & $\begin{array}{l}\text { Women } \\
\text { Short }\end{array}$ & Long $\dagger$ & Total \\
\hline $20-29$ & 9 & 4 & 13 & 3 & 3 & 6 \\
$30-39$ & 6 & 5 & 11 & 5 & 2 & 7 \\
$40-49$ & 8 & 9 & 17 & 2 & 5 & 7 \\
$50-59$ & 14 & 7 & 21 & 5 & 7 & 12 \\
$60-69$ & 15 & 9 & 24 & 9 & 8 & 17 \\
$70-79$ & 13 & 7 & 20 & 12 & 12 & 24 \\
$80-89$ & 9 & 5 & 14 & 6 & 5 & 11 \\
\hline Total & 74 & 46 & 120 & 42 & 42 & 84
\end{tabular}

«Number of cases with a left coronary artery trunk of $11 \mathrm{~mm}$ or shorter.

$\dagger$ Number of cases with a left coronary artery trunk of $12 \mathrm{~mm}$ or longer.

circumflex, and right coronary artery were classified in the following five degrees of severity.

0 : No atherosclerosis present.

I : Atherosclerosis resulting in luminal narrowing of less than 25 per cent.

II : Atherosclerosis resulting in luminal narrowing between 25 and 50 per cent.

III : Atherosclerosis resulting in luminal narrowing between 50 and 75 per cent.

IV : Atherosclerosis resulting in narrowing from 75 per cent up to complete occlusion of the lumen.

Where multiple lesions were present in any of the above major branches, the most severe one was taken into consideration.

The length of the main left coronary artery, the heart's weight, the maximum thickness of the free left ventricular wall and the height of each individual were also measured.

Measurements and evaluations were done by at least two independent observers. Whenever there was disagreement, the average of the estimates was taken into consideration.

\section{Statistical analysis}

Since data regarding severity of atherosclerosis were grouped in five grades those of the main left coronary artery's length were also grouped, and correlation coefficients were estimated by a grouped frequency table (Hill, 1971). Differences between mean values were evaluated by the Student's $\mathrm{t}$ test. Differences between proportions were assessed for significance by using the $\chi^{2}$ test.

\section{Results}

The length of the left coronary artery trunk ranged from 0 to $24 \mathrm{~mm}$, mean $11.02 \pm 4.5 \mathrm{~mm}$.

Fig. 1 shows the average degree of atherosclerosis

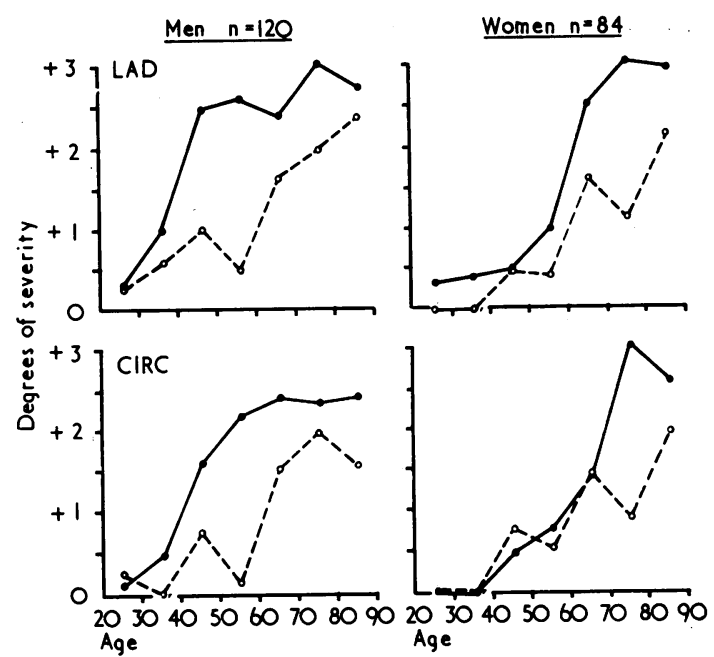

FIG. 1 Average degree of coronary atherosclerosis related to age and sex group in the left anterior descending ( $L A D)$ and circumflex (CIRC) branches of the left coronary artery. There is a gap with advancing age between the degree of atherosclerosis in cases with a left coronary artery trunk of $11 \mathrm{~mm}$ or shorter (solid lines) as compared with that in cases with a left coronary artery trunk of $12 \mathrm{~mm}$ or more (interrupted lines).

in the two branches of the left coronary artery as evolving with age in each sex group. Data from cases with a left coronary artery trunk longer than the above-mentioned mean length are shown separately from those with a shorter one. The distribution of cases with a short and with a long left coronary artery per age and sex is given in Table 1. As seen in Fig. 1, with advancing age, particularly after the fifth decade of life, there is a dissociation between the curves of severity of atherosclerosis, with an early rise and a higher rate of development in cases with a short left coronary artery trunk.

Table 2 shows the mean length of the left coronary artery trunk corresponding to each degree of atherosclerosis in the left anterior descending and circumflex branches. Since the incidence of coronary atherosclerosis is low for the young Greek population studied, only cases over the age of 50 were included in the Table. It is seen that the higher the degree of atherosclerosis, the shorter is the corresponding mean length of the main left coronary artery. After grouping data for moderate (grades I and II) and severe (grade III and IV) atherosclerosis, differences between the 
TABLE 2 Length of left coronary artery trunk ( $\mathrm{mm}$ ) and degree of atherosclerosis

\begin{tabular}{|c|c|c|c|c|c|c|c|c|}
\hline $\begin{array}{l}\text { Degree of } \\
\text { atherosclerosis }\end{array}$ & $\begin{array}{l}\text { Left ant } \\
\text { Mean } \\
\text { length }\end{array}$ & $\begin{array}{r}\text { or descer } \\
\pm 1 S I\end{array}$ & $\begin{array}{l}\text { ding } \\
\text { No. }\end{array}$ & $P<$ & $\begin{array}{l}\text { Circumflex } \\
\text { Mean } \\
\text { length }\end{array}$ & $\pm 1 S D$ & No. & $P<$ \\
\hline 0 & $15 \cdot 33$ & 3.84 & 24 & ---- & $13 \cdot 72$ & $5 \cdot 17$ & 39 & --- \\
\hline I & 12.69 & $4 \cdot 74$ & 29 & \multirow{2}{*}{0.001} & $11 \cdot 48$ & 3.51 & 23 & \multirow{2}{*}{0.025} \\
\hline II & $10 \cdot 38$ & $4 \cdot 21$ & 23 & & $11 \cdot 40$ & $5 \cdot 21$ & 20 & \\
\hline$I+I I$ & 11.85 & 4.61 & 52 & $--^{2}--$ & $11 \cdot 44$ & $4 \cdot 38$ & 43 & $--^{v}--$ \\
\hline III & $9 \cdot 17$ & 3.9 & 30 & \multirow{2}{*}{0.001} & $9 \cdot 0$ & $4 \cdot 12$ & 35 & \multirow{2}{*}{0.025} \\
\hline IV & $8 \cdot 32$ & $4 \cdot 15$ & 37 & & 8.65 & 3.73 & 26 & \\
\hline $\mathrm{III}+\mathrm{IV}$ & $8 \cdot 70$ & 4.06 & 67 & $-{ }^{\vee}--$ & 8.85 & 3.97 & 51 & - \\
\hline
\end{tabular}

corresponding mean lengths of the left coronary artery trunk were significant.

In Fig. 2 and 3 the distribution of cases included in Table 2 is shown, as well as the corresponding regression lines and their 95 per cent confidence limits. The degree of severity of atherosclerosis in the left anterior descending branch (Fig. 2) was inversely related to the length of the main left coronary artery. The correlation coefficient was -0.527 , differing from zero at a significant level of probability $(P<0.001)$.

The degree of severity of atherosclerosis in the circumflex branch (Fig. 3) was also inversely related to the length of the main left coronary artery. The correlation coefficient was -0.428 $(P<0.001)$. The relation between the length of the main left coronary artery and the degree of atherosclerosis in the right coronary artery was also studied. As expected, no significant correlation was found between these two variables $(r=0 \cdot 166$, $P>0.05$ ). Similarly, no relation was found between the main left coronary artery's length and the heart's weight, thickness of the free left ventricular wall, and the individual's height, age, and sex.

Table 3 shows the number of patients who died from myocardial infarction and those who died from other causes in relation to the length of the left coronary artery trunk. In the group of cases without myocardial infarction the ratio of persons with either short or long trunks is $1: 1$, while in the group of cases with myocardial infarction the ratio is about $3: 1$. This difference was significant $(0.01<P<0.02)$. The mean length of the left coronary artery trunk in cases with myocardial infarction aged over 50 years $(\mathrm{N}=45)$ was $9.9 \pm 1$ $\mathrm{mm}$, while in the cases without evidence of atherosclerosis ( 0 grade) in left coronary artery branches in the same age group $(\mathrm{N}=20)$ was $15 \cdot 1 \pm 3.86 \mathrm{~mm}$. The difference between the above two means was highly significant $(P<0.001)$.

\section{Discussion}

Our previous study based on coronary arteriographic findings (Gazetopoulos et al., 1976) and the present one based on pathological observations suggest that a long main left coronary artery exerts some protective action against the development of atherosclerosis in its branches. The mechanisms involved seem likely to be related to modification of mechanical and hydraulic factors resulting from difference in the length of the left coronary artery trunk.

That local mechanical and haemodynamic factors may be relevant to the development of atherosclerosis is indicated by the fact that the greatest atherogenic effect tends to appear in sites of predilection, such as bifurcations, branchings, bends, and narrowings, where mechanical stresses are likely to be higher (Schlesinger and Zoll, 1941; Willis, 1954; Duguid and Robertson, 1957; Schwartz and Mitchell, 1962; Pitt et al., 1963; Caro, Fitz-Gerald, and Schroter, 1969).

Increased pressure (Clawson, 1939; Glagov, Rowley, and Kohut, 1961; Kannel, Schwartz, and McNamara, 1969), increased flow rate (Fox and Hugh, 1966; Gyurko and Szabo, 1969), several variables related to changes of pressure and flow (Sako, 1962; Scharfstein, Gutstein, and Lewis, 1963; Glagov, 1972; Texon, 1974), and systolic motion resulting in curving of the coronary vessels (Fulton, 1965; Glagov, 1972) have been suggested as factors creating mechanical conditions initiating 
or accelerating the development of atherosclerosis in these sites of predilection.

Poiseuille's law relates the drop in pressure $(\Delta P)$ along a vessel's lumen to its length $(L)$ : $\Delta P=\frac{8 \mathrm{~L}}{\pi \mathrm{r}^{4}} . \mathrm{F} \cdot \mathrm{v}$ ( $\mathrm{r}$ : radius, $\mathrm{F}$ : flow, $\mathrm{v}$ : viscosity). Furthermore, as provided by the above formula flow rate $(F)$ is inversely proportional to a vessel's length. Though Poiseulle's law cannot be quantitatively applied to the circulatory system, it is reasonable to suggest that a long main left coronary artery, by decreasing the pressure and probably flow velocity, decreases the forces acting on its branching area and beyond it.

Another factor that could be involved is the

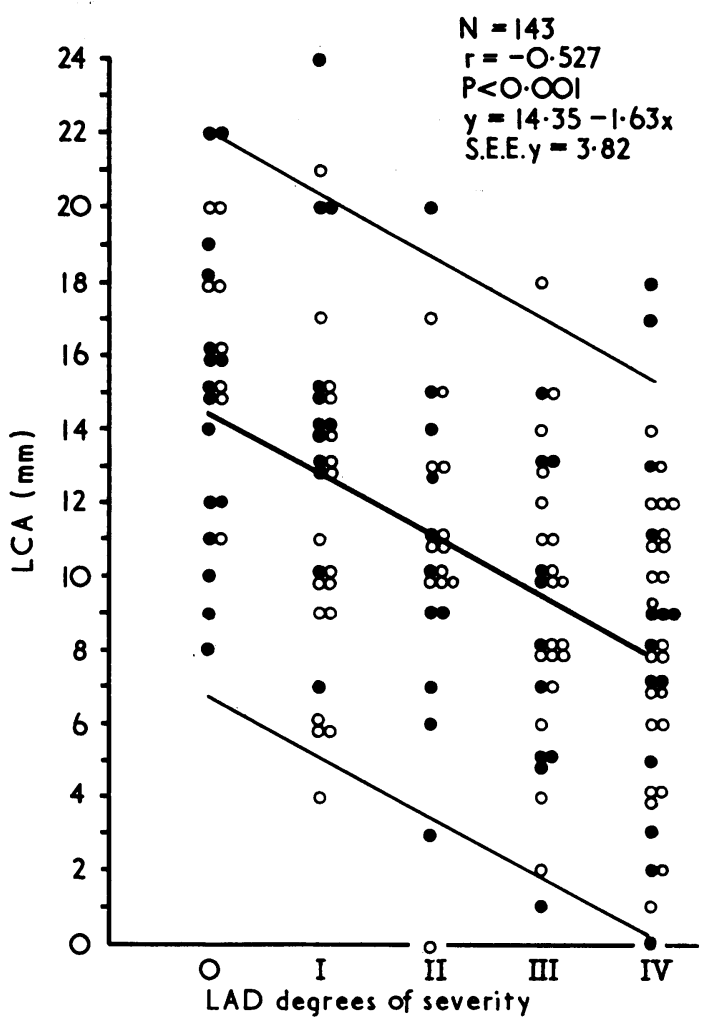

FIG. 2 Relation between the length of the left coronary artery trunk and the degree of severity of atherosclerosis in the left anterior descending branch in men (open circles) and women (closed circles) aged over 50 years. The regression line is paralleled by the 95 per cent confidence limits (two Standard Errors of Estimate). The correlation coefficient $(r)$ differs significantly from zero.
TABLE 3 Length of left coronary artery trunk and relation to death from myocardial infarction

\begin{tabular}{lll}
\hline Cause of death & $\begin{array}{l}\text { Short* } \\
\text { LCAT } \\
\text { (No. of cases) }\end{array}$ & $\begin{array}{l}\text { Long } \\
\text { LCAT }\end{array}$ \\
\hline $\begin{array}{ll}\text { Myocardial infarction } \\
\begin{array}{l}\text { Other than myocardial } \\
\text { infarction }\end{array}\end{array}$ & 33 & 12 \\
\hline
\end{tabular}

$\star 11 \mathrm{~mm}$ or shorter

$+12 \mathrm{~mm}$ or longer.

LCAT = Left coronary artery trunk.

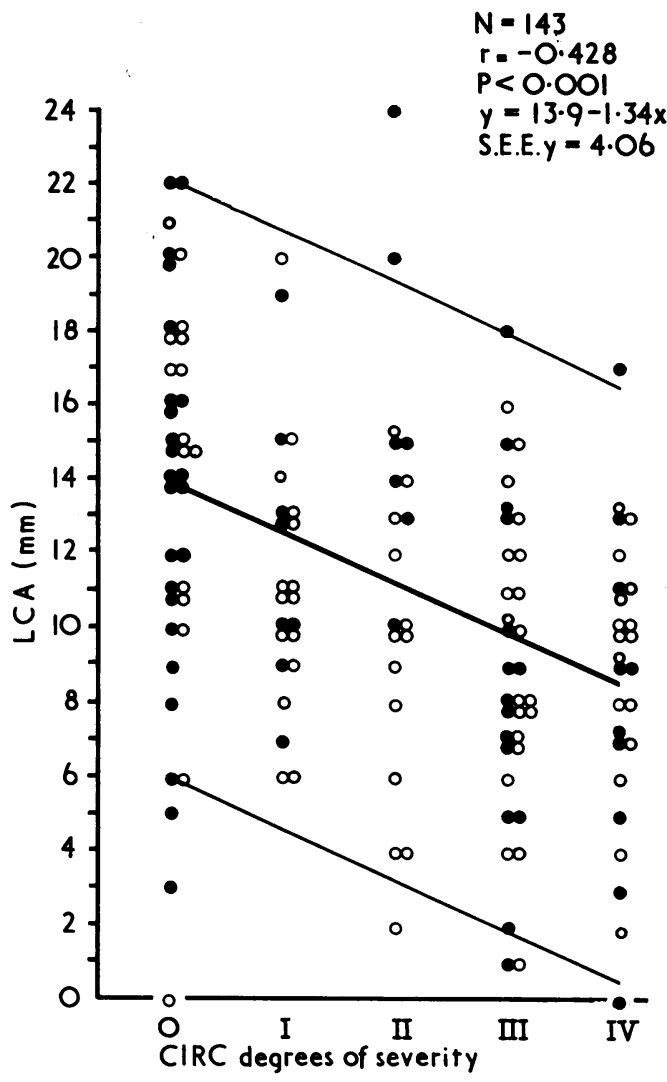

FIG. 3 Relation between the length of the left coronary artery trunk and the degree of atherosclerosis in the circumflex branch in men (open circles) and women (closed circles) aged over 50 years. The regression line is paralleled by the 95 per cent confidence limits (2 Standard Errors of Estimate). The correlation coefficient $(r)$ differs significantly from zero. 
vessel's compliance which is proportional to the change of its volume determined by the vessel's calibre and length. Thus, it is likely that the main left coronary artery would absorb part of the systolic pressure and flow wave and return it later to a degree depending on the vessel's length. This damping effect, exercised at the bifurcation area, would decrease the peak systolic pressure, pulse pressure, peak flow velocity, and rate of change in flow velocity, factors that have been implicated in the development of atherosclerosis (Texon, 1974).

Sites of bending, knuckling, and narrowing of the coronary arteries during the heart's action are also subject to atherogenic effect (Fulton, 1965; Glagov, 1972). The initial part ('neck') of the left anterior descending tethered proximally by its origin from the main left coronary artery and distally by its first myocardial branch is subject to a higher risk of bending and knuckling than the epicardial portion of the other coronary arteries (Fulton, 1965; Lewis et al., 1970). Therefore, it is conceivable that the shorter the left coronary artery trunk, the longer the free unattached part of the left anterior descending branch would be. Thus, during systole it would become more bent or kinked than if it were a short one, as in cases with a long left coronary artery.

Even without considering the possibility of a lumen's narrowing during systolic kinking, the formed curve alone is expected to modify hydraulic conditions across the lumen of the curved vessel. The centrifugal forces applied at the curved area would increase the lateral pressure along the outer wall, while at the same time they would diminish the pressure along the inner wall (Texon, 1957.). On the other hand, in a curved vessel, axial layers of high flow velocity are impinging on the outer wall (Glagov, 1972). Increased flow rate, according to Fry $(1968,1969)$ causes injury or detachment of the endothelium undergoing the stress of the shearing forces, or according to Texon $(1963,1972)$ preatherosclerotic intimal proliferation by 'suction effect' at low pressure areas produced by the increased flow.

The above-mentioned factors, i.e. systolic bending and curving of the left anterior descending, can serve as a possible explanation as to why this vessel and especially its first free portion is frequently involved by atherosclerosis (Schlesinger and Zoll, 1941; Pitt et al., 1963; Vlodaver and Edwards, 1974) and how this predilection can be exaggerated when the left coronary artery trunk is short.

Relation between a short left coronary artery trunk and coronary atherosclerosis is a finding not previously reported. The only relevant hint was presented by Lewis et al. (1970) where in 11 out of 12 cases with electrocardiographic evidence of a left bundle-branch block a main left coronary artery trunk, less than $6 \mathrm{~mm}$ long, was found by coronary arteriographic means. This was attributed to inadequacy in blood supply to the left bundle, resulting from increased systolic kinking caused by the short left coronary artery trunk. Though confirmation by other investigators (Hamby, Tabrah, and Gupta, 1973) was not so extensive; in our previous report all 4 cases with left bundle-branch block had a short main left coronary artery (Gazetopoulos et al., 1976).

The scatter of our data around the regression line is large, as can be seen in Fig. 2 and 3, and the magnitude of correlation is not impressive. But it would be surprising if this were not so, in view of the number of other factors involved in the development of coronary artery disease. However, it must be noted that mechanical and haemodynamic changes deriving from anatomical variations in the structure of the arterial tree have been proposed as basic factors in the initiation of atherosclerosis. The rest of the known predisposing factors have been considered as secondary or simply modifying the atherogenic process (Altschule, 1974; Texon, 1974).

The present study enhances the previous findings (Gazetopoulos et al., 1976), that the length of the main left coronary artery is an anatomical factor which may influence the rate of development of atheromatosis on its branches. Since anatomical structure and distribution of the coronary arteries is possibly determined by heredity, as are other morphological characteristics, the length of the main left coronary artery could be considered a heriditary factor predisposing to coronary artery disease.

\section{References}

Altschule, M. D. (1974). The etiology of atherosclerosis. Medical Clinics of North America, 58, 397.

Caro, C. G., Fitz-Gerald, J. M., and Schroter, J. C. (1969). Arterial wall shear and distribution of early atheroma in man. Nature (London), 223, 1159.

Clawson, B. J. (1939). Coronary sclerosis. An analysis of 928 cases. American Heart fournal, 17, 387.

Duguid, J. B., and Robertson, W. B. (1957). Mechanical factors in atherosclerosis. Lancet, 1, 1205.

Fox, J. A., and Hugh, A. E. (1966). Localization of atheroma: a theory based on boundary layer separation. British Heart fournal, 28, 388.

Fry, D. L. (1968). Acute vascular endothelial changes associated with increased blood velocity gradients. Circulation Research, 22, 165.

Fry, D. L. (1969). Certain histological and chemical responses of the vascular interface to acutely induced mechanical stress in the aorta of the dog. Circulation Research, 24, 93

Fry, D. L. (1972). Localizing factors in arteriosclerosis. In Atherosclerosis and Coronary Heart Disease, p. 85. Ed. by W. Likoff, B. L. Segal, and W. Insull. Grune and Stratton New York. 
Fulton, W. F. M. (1965). The Coronary Arteries. p. 64. Charles C Thomas, Springfield, Illinois.

Gazetopoulos, N., Ioannidis, P. J., Marselos, A., Kelekis, D. Lolas, C., Avgoustakis, D., and Tountas, C. (1976). Length of the main left coronary artery in relation to atherosclerosis of its branches. British Heart fournal, $38,180$.

Glagov, S. (1972). Hemodynamic risk factors: mechanical stress, mural architecture, medical nutrition and the vulnerability of arteries to atherosclerosis. In The Pathogenesis of Atherosclerosis, p. 164 . Ed. by R. W. Wissler and J. C. Geer. Williams and Wilkins, Baltimore.

Glagov, S., Rowley, D. A., and Kohut, R. I. (1961). Atherosclerosis of the human aorta and its coronary and renal arteries. Archives of Pathology, 72, 558.

Gyurko, G., and Szabo, M. (1969). Experimental investigations of the role of hemodynamic factors in formation of intimal changes. Surgery, 66, 871.

Hamby, R. J., Tabrah, F., and Gupta, M. (1973). Intraventricular conduction disturbances and coronary artery disease. Clinical hemodynamic and angiographic study. American fournal of Cardiology, 32, 758.

Hill, A. B. (1971). Principles of Medical Statistics, 9th ed., p. 195. The Lancet, London.

Kannel, W. B., Schwartz, M. J., and McNamara, P. M. (1969). Blood pressure and risk of coronary heart disease. The Framingham study. Diseases of the Chest, 56, 43.

Lewis, C. M., Dagenais, G. R., Friesinger, G. C., and Ross, R. S. (1970). Coronary arteriographic appearances in patients with left bundle-branch block. Girculation, 41, 299.

Pitt,"B., Zoll, P. M., Blumgart, H. L., and Freiman, D. G. (1963). Location of coronary arterial occlusions and their relation to the arterial pattern. Circulation, 28, 35.

Sako, Y. (1962). Effects of turbulent blood flow and hypertension on experimental atherosclerosis. Fournal of the American Medical Association, 179, 36.
Scharfstein, H., Gutstein, W. H., and Lewis, L. (1963), Changes of boundary layer flow in model systems: implications for initiation of endothelial injury. Circulation Research, 13, 580 .

Schlesinger, M. J., and Zoll, P. M. (1941). Incidence and localization of coronary artery occlusions. Archives of Pathology, 32, 178.

Schwartz, C. J., and Mitchell, R. A. (1962). Observation on localization of arterial plaques. Circulation Research, 11, 63.

Stehbens, W. E. (1975). The role of hemodynamics in the pathogenesis of atherosclerosis. Progress in Cardiovascular Diseases, 18, 89 .

Texon, M. (1957). A hemodynamic concept of atherosclerosis with particular reference to coronary occlusion. Archives of Internal Medicine, 99, 418 .

Texon, M. (1963). The role of vascular dynamics in the development of atherosclerosis. In Atherosclerosis and its Origin, p. 167. Ed. by M. Sandler and G. H. Bourne. Academic Press, New York.

Texon, M. (1972). The hemodynamic basis of atherosclerosis. Further observations: the ostial lesion. Bulletin of the New York Academy of Medicine, 48, 733.

Texon, M. (1974). Atherosclerosis. Its hemodynamic basis and implications. Medical Clinics of North America, 58, 257.

Vlodaver, Z., and Edwards, J. E. (1974). Pathology of coronary atherosclerosis. Progress in Cardiovascular Diseases, 14, 256.

Willis, G. C. (1954). Localizing factors in atherosclerosis. Canadian Medical Association fournal, 70, 1.

Requests for reprints to D $\ddot{r}$. N. Gazetopoulos, Athens University, Aretaeion Hospital, 76 Vas. Sophias Avenue, Athens (611), Greece. 